\title{
Effects of Substrate Pulse Bias Duty Cycle on the Microstructure and Mechanical Properties of Ti-Cu-N Films Deposited by Magnetic Field-Enhanced Arc Ion Plating
}

\author{
Sheng-Sheng Zhao ${ }^{1} \cdot$ Yan-Hui Zhao $^{2} \cdot$ Lv-Sha Cheng $^{1} \cdot$ Vladimir Viktorovich Denisov $^{3} \cdot$ \\ Nikolay Nikolaevich Koval ${ }^{3}$ - Bao-Hai $\mathrm{Yu}^{2} \cdot \mathrm{Hai}^{-J u a n} \mathrm{Mei}^{1}$
}

Received: 30 October 2016/Revised: 19 November 2016/Published online: 6 February 2017

(c) The Chinese Society for Metals and Springer-Verlag Berlin Heidelberg 2017

\begin{abstract}
Ti}-\mathrm{Cu}-\mathrm{N}$ films were deposited on 316L stainless steel substrates by magnetic field-enhanced arc ion plating. The effect of substrate pulse bias duty cycle on the chemical composition, microstructure, surface morphology, mechanical and tribological properties of the films was systemically investigated. The results showed that, with increasing the duty cycle, $\mathrm{Cu}$ content decreases from 3.3 to 0.58 at.\%. XRD results showed that only TiN phase is observed for all the deposited films and the preferred orientation transformed from $\mathrm{TiN}(200)$ to $\mathrm{TiN}(111)$ plane with the increase in duty cycle. The surface roughness and deposition rate showed monotonous decrease with increasing the duty cycle. The residual stress and hardness firstly increase and then decrease afterwards with the increase in duty cycle, while the variation of critical load shows reverse trend. Except for the film with duty cycle of $10 \%$, others perform the better wear resistance.
\end{abstract}

KEY WORDS: Magnetic field; Arc ion plating; Ti-Cu-N film; Residual stress; Hardness

\section{Introduction}

TiN hard films have been successfully used in the cutting and forming tool industries due to their superior wear resistant and corrosion-resistant properties. With the development of industry, mechanical and tribological properties of TiN films cannot meet requirements of difficult-to-cut material [1,2], so hard nanocomposite protective films have attracted considerable attention in recent years $[3,4]$. The hard nanocomposite films are generally

Available online at http://link.springer.com/journal/40195

Sheng-Sheng Zhao

sszhao@szpt.edu.cn

1 School of Mechanical and Electrical Engineering, Shenzhen Polytechnic, Shenzhen 518055, China

2 Institute of Metal Research, Chinese Academy of Sciences, Shenyang 110016, China

3 Institute of High Current Electronics, Siberian Branch, Russian Academy of Sciences, Akademicheskii pr. 2/3, Tomsk, Russia 634055 divided two types. One is nc-MeN/hard phase nanocomposite, such as nc-TiN/a-Si $\mathrm{N}_{4}$ and nc-TiN/a-TiB ${ }_{2}$, and the other is nc-MeN/soft phase (such as $\mathrm{Cu}, \mathrm{Ni}, \mathrm{Y}$ and $\mathrm{Ag}$.) [5]. Here nc- and a- stand for the nanocrystalline and amorphous phase, respectively, and $\mathrm{Me}=\mathrm{Ti}, \mathrm{W}, \mathrm{Zr}, \mathrm{Cr}, \mathrm{Mo}$, $\mathrm{Al}$, etc., are elements synthesizing hard nitrides. $\mathrm{Ti}-\mathrm{Cu}-\mathrm{N}$ nanocomposite films as a typical nc-MeN/soft phase film have been widely investigated due to their excellent mechanical properties [6]. Recent reports also pointed out $\mathrm{Ti}-\mathrm{Cu}-\mathrm{N}$ nanocomposite films exhibited very good antibacterial properties [7].

Various physical vapour deposition (PVD) techniques have been used to prepare $\mathrm{Ti}-\mathrm{Cu}-\mathrm{N}$ nanocomposite films [8-10]. Arc ion plating (AIP) technique is one of the most prospective PVD techniques for large-scale industrial application of $\mathrm{Ti}-\mathrm{Cu}-\mathrm{N}$ films because of the high degree of ionization in the target material, the easy control of the parameters and the high deposition rate. However, some problems of conventional DC-biased AIP are universally recognized, such as droplet contamination, high substrate temperature and large residual stress, due to continuous ion bombardment on the substrate during the deposition. 
Pulsed bias was then introduced into AIP to solve the problems and improve film quality [11-13].

In previous work, we also successfully deposited the Ti$\mathrm{Cu}-\mathrm{N}$ nanocomposite films on high-speed-steel substrates by pulse bias arc ion plating (PBAIP) [14] and designed a magnetic field-enhanced arc ion plating system with pulse bias (MFE-AIP) [15, 16]. The system, keeping all the merits of conventional AIP, brings new features such as macro-particle cleaning due to faster arc spot movement speed, film compactness promoting due to higher ionic charge density, as well as increased deposition rate due to more focused ion beam. As is well known, the properties of films can be optimized by selecting proper pulse bias parameters, e.g. voltage amplitude, duty cycle or pulse frequency [17-20]. The pulse bias duty cycle is the fraction of time that a pulse bias voltage is in an "active" state during one period and decides the quantity of plasma accelerated by bias electric field. However, there is little research for the effects of substrate pulse bias duty cycle on the microstructure and mechanical properties of $\mathrm{Ti}-\mathrm{Cu}-\mathrm{N}$ films.

In this present work, $\mathrm{Ti}-\mathrm{Cu}-\mathrm{N}$ films were deposited on 316 $\mathrm{L}$ stainless steel by MFE-AIP. And then, the influence of the pulse bias duty cycle on surface morphology, microstructure and mechanical properties of the films was systematically investigated.

\section{Experimental}

\subsection{Deposition of Ti-Cu-N Films}

The Ti-Cu-N films were deposited on commercial mirrorpolished $316 \mathrm{~L}$ stainless steel sheets $(30 \mathrm{~mm} \times$ $30 \mathrm{~mm} \times 0.8 \mathrm{~mm}$ and $50 \mathrm{~mm} \times 10 \mathrm{~mm} \times 0.8 \mathrm{~mm}$ ) by the magnetic field-enhanced arc ion plating system [15]. The modulus of elasticity $E_{\mathrm{s}}$ and Poisson ratio $v_{\mathrm{s}}$ of the substrates is $195 \mathrm{GPa}$ and 0.3 , respectively. The schematic

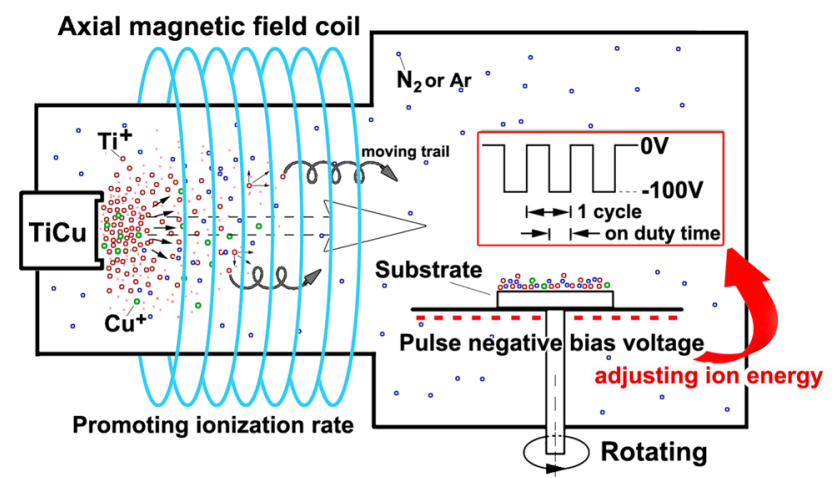

Fig. 1 Schematic view of the magnetic field-enhanced arc ion plating system used to deposit $\mathrm{Ti}-\mathrm{Cu}-\mathrm{N}$ films diagram of this vacuum system is shown in Fig. 1. The target material was $\mathrm{TiCu}$ alloy (Ti/Cu-90:10 at.\%) with purity of $99.99 \%$. The axial magnetic field can be produced by an adjustable electromagnetic coil located outside and twined around the chamber. By regulating the coil current, the magnetic field strength can be controlled. And the magnetic induction was determined by a SHT-V magnetometer. The work gas was high-purity nitrogen (99.99 at.\%) and high-purity argon (99.99 at.\%), respectively. Prior to the film deposition, the base pressure of chamber was $5.0 \times 10^{-3} \mathrm{~Pa}$, and then $\mathrm{Ar}$ (gas pressure $0.3 \mathrm{~Pa}$ ) was introduced to etch the substrate. Subsequently, $\mathrm{Ti}$ and $\mathrm{Cu}$ ions bombardment at a $-600 \mathrm{~V}$ dc bias voltage was applied for 5 min with $70 \mathrm{~A}$ target arc current to improve the film/substrate adhesion.

During deposition, the pulse bias duty cycles were set as $10 \%, 30 \%, 50 \%, 70 \%$ and $80 \%$, respectively, in order to study their influence on film properties. The other deposition parameters were kept constant: $\mathrm{N}_{2}$ pressure 1.0 $\mathrm{Pa}$, the pulsed bias amplitude $-100 \mathrm{~V}$ with $40 \mathrm{kHz}$ frequency, the arc currents $70 \mathrm{~A}$, the distance between the target and substrate $300 \mathrm{~mm}$, the magnetic field intensity $10 \mathrm{mT}$, the substrate temperature $T_{\mathrm{s}}$ about $300{ }^{\circ} \mathrm{C}$ and the total deposition time $40 \mathrm{~min}$.

\subsection{Characterization of Ti-Cu-N Films}

The chemical composition was examined by X-ray photoelectron spectroscopy (XPS, ESCALAB250), with $\mathrm{Ar}^{+}$ of sputtering voltage of $2 \mathrm{kV}$ for $10 \mathrm{~min}$. The microstructure analysis was carried out by X-ray diffraction (XRD, Rigaku, Japan, D/max2400 with $\mathrm{Cu} K_{\alpha}=0.154056 \mathrm{~nm}$ ). The cross-sectional images and diffractions were obtained by a Tecnai G2 F20 S-Twin transmission electron microscope (TEM). The surface morphology and cross-sectional images of $\mathrm{Ti}-\mathrm{Cu}-\mathrm{N}$ films were characterized by a Zeiss Supra 55 scanning electron microscopy (SEM). The deposition rate was calculated according to the SEM crosssectional images. The surface roughness $R_{\mathrm{a}}$ was determined by a KLA-Tencor Alpha-Step IQ surface profiler.

Hardness $(H)$ and elastic modulus $\left(E^{*}\right)$ measurements were taken by using a nanoindenter (Nano Indenter G200, Agilent Technologies) with a Berkovich diamond tip, the maximum applied load was $20 \mathrm{mN}$, and the indent depth was lower than $10 \%$ of film thickness. The residual stresses of the films were determined by substrate curvature technique [21]. The adhesion between the film and substrate was tested using a WS-2005 Automatic scratch tester with a loading speed of $100 \mathrm{~N} \mathrm{~min}^{-1}$. The critical loads were determined from the acoustic signal.

The sliding wear resistance was tested using a MST3000 ball-on-disc tribometer. During the test, an alumina ball $(4.0 \mathrm{~mm}$ in diameter) was used as the counter face. 
The tests were carried out with a sliding speed of $0.06 \mathrm{~m} \mathrm{~s}^{-1}$ with a normal load of $5 \mathrm{~N}$. The total testing time was $20 \mathrm{~min}$ (6 $\mathrm{mm}$ in diameter of wear track). The test temperature was about $(25 \pm 3){ }^{\circ} \mathrm{C}$, and the relative humidity was about $30 \%$. The friction coefficient was directly obtained from measurement record. The dimensions of wear tracks were tested by a KLA-Tencor AlphaStep IQ surface profiler. The wear rate $k$ can be calculated by the following formula [22]:

$k=V /(S L)$.

where $V$ is the wear volume calculated according to the dimensions of wear tracks, and $S$ and $L$ are the total sliding distance and the imposed load, respectively.

\section{Results and Discussion}

\subsection{Chemical Composition}

Negative pulse bias is usually used to produce an electric field with pulse mode (not d.c. mode) and to increase the energy and quantity of plasma reaching substrates. When the pulse is "on", a pulse sheath can be produced and all the positively charged ions entered into the pulse sheath will be accelerated to obtain more energy. The duty cycle is a ratio of pulse duration to a complete cycle period. The bigger is the duty cycle, the more quantity of plasma will be accelerated, at the same time the higher is the average energy of plasma reaching substrates. The atomic content in the Ti-Cu-N films is shown in Fig. 2. The result showed that the content of $\mathrm{Cu}$ appeared to decrease from 3.3 to 0.58 at.\% with substrate pulse bias duty cycle increasing from $10 \%$ to $80 \%$. The content of $\mathrm{Ti}$ and $\mathrm{N}$ appeared to slightly decrease and remarkably increase, respectively, with increasing duty cycle. Sundgren's study already pointed out that the energy of the charged particle

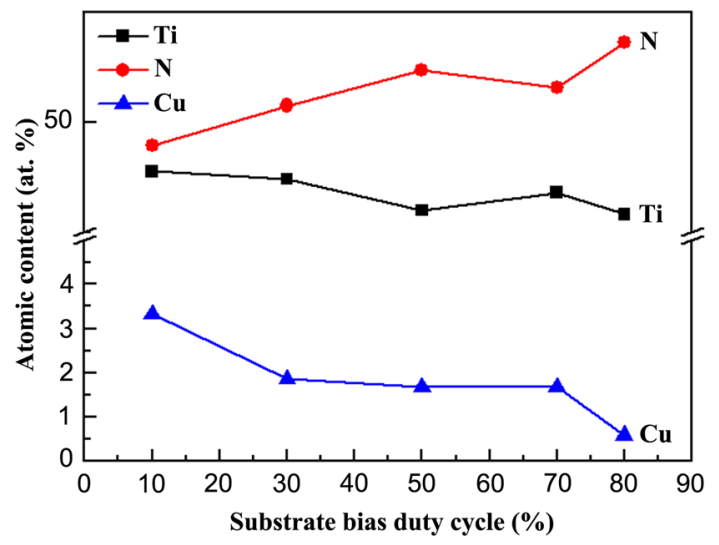

Fig. 2 Chemical compositions (at.\%) of $\mathrm{Ti}-\mathrm{Cu}-\mathrm{N}$ films plotted as a function of duty cycle impinging on the substrate increased as the bias voltage increased [23]. Because the sputtering yield increased with energy, more materials were resputtered with the increase in pulse bias duty cycle. It is shown that the sputtering yield of $\mathrm{Cu}$ is higher than that of $\mathrm{Ti}$ [24]. Therefore, the decrease in the atomic fraction of $\mathrm{Cu}$ was attributed to the discriminatory resputtering of $\mathrm{Cu}$ atoms. Meanwhile, the decrease in the atomic fraction of $\mathrm{Ti}$ would also be related to the resputtering effect with increasing the duty cycle, and in comparison with the results of $\mathrm{Ti}$ and $\mathrm{Cu}$ content, $\mathrm{N}$ content would be therefore increased.

For further understanding the phase composition and the possible chemical bonding states of $\mathrm{Cu}$ in the $\mathrm{Ti}-\mathrm{Cu}-\mathrm{N}$ films, Cu2p XPS spectra for the film with duty cycle 50\% are presented in Fig. 3. The Cu2p peaks appear at $932.4 \mathrm{eV}$ and $933.1 \mathrm{eV}$ for $\mathrm{Cu} 2 \mathrm{p}_{3 / 2}$ and $952.4 \mathrm{eV}$ for $\mathrm{Cu} 2 \mathrm{p}_{1 / 2}$. Tian et al. [25] observed the peaks of $\mathrm{Cu} 2 \mathrm{p}_{3 / 2}$ at $932.7 \mathrm{eV}$ and $933.8 \mathrm{eV}$, and Wang et al. [26] surveyed the peaks of $\mathrm{Cu} 2 \mathrm{p}_{3 / 2}$ at $931.8 \mathrm{eV}$ and $\mathrm{Cu} 2 \mathrm{p}_{1 / 2}$ at $951.9 \mathrm{eV}$. Both of them attributed these results to pure metallic $\mathrm{Cu}$. Therefore, in this present work we suggest that $\mathrm{Cu}$ exists mainly in the form of free copper in the films.

\subsection{Microstructure}

For the evaluation of microstructures of the $\mathrm{Ti}-\mathrm{Cu}-\mathrm{N}$ films under different pulse bias duty cycles, XRD spectrum tests were performed. Figure 4 shows XRD patterns of the Ti$\mathrm{Cu}-\mathrm{N}$ films. It is clear that all results only show the diffraction peaks that can be allocated to cubic TiN. There is not any diffraction peak from copper to be observed, excluding the possible superposition of $\mathrm{TiN}(200)$ with $\mathrm{Cu}(111)$. It is extremely hard to distinguish them due to their similar crystalline interplanar spacing [6]. In addition, it is also the possible reason that fairly low content and very fine grain size of $\mathrm{Cu}$ in the films. As shown in the figure, the films exhibited a relatively strong $\operatorname{TiN}(200)$

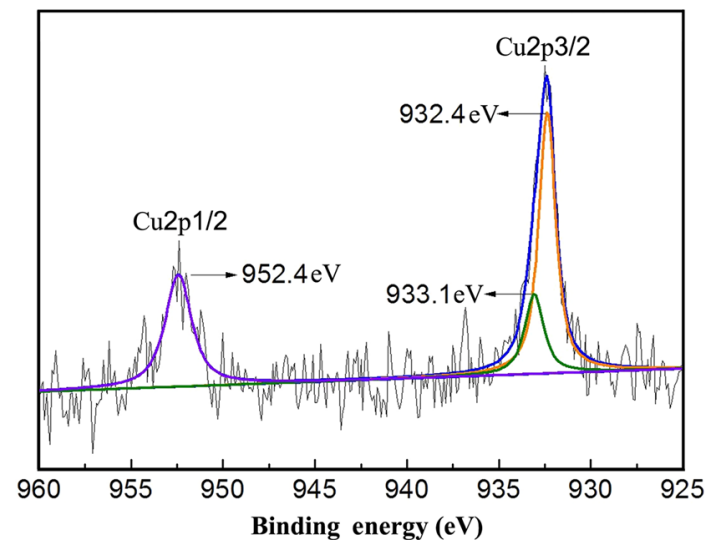

Fig. 3 X-ray photoelectron spectral details collected from the $\mathrm{Ti}-$ $\mathrm{Cu}-\mathrm{N}$ film with duty cycle of $50 \%$ 


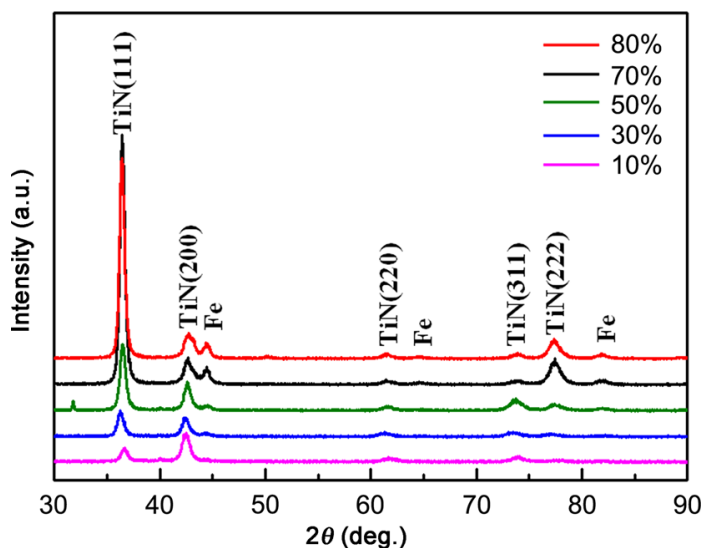

Fig. 4 X-ray different patterns of the $\mathrm{Ti}-\mathrm{Cu}-\mathrm{N}$ films prepared under different bias duty cycle

orientation plane at pulse bias duty cycle of $10 \%$, and the texture of the films transformed from $\mathrm{TiN}(200)$ preferred orientation to $\mathrm{TiN}(111)$ with pulse bias duty cycle increasing from $30 \%$ to $50 \%$. Specially, for the films with $70 \%$ and $80 \%$ duty cycles, the (222) diffraction peak also occurred. Conclusively, the enhanced pulse bias duty cycle is beneficial for TiN(111) preferred orientation of the Ti$\mathrm{Cu}-\mathrm{N}$ films. The intensity of peak of Fe from the substrates gradually increased with duty cycle, which implied that the thickness of the films decreased.

As we know, for PVD deposition, in order to minimize the films' total energy (includes surface energy and strain energy) during their growth, preferred orientation of the films will be formed [27, 28]. For films with both fec- and $\mathrm{NaCl}$-type structure, the surface energy $\left(S_{h k l}\right)$ changes with the preferred orientation as $S_{111}>S_{220}>S_{200}$ [29], while the strain energy $\left(U_{h k l}\right)$ converts with the preferred orientation as $U_{200}>U_{220}>U_{111}$ [30]. In this study, for minimizing the total energy in the $\mathrm{Ti}-\mathrm{Cu}-\mathrm{N}$ films during their growth, the (200) orientation was dominant for the lowest surface energy when bias duty cycle (i.e. lower ions energy) lowered. With bias duty cycle increasing (i.e. ions energy increasing), the (111) orientation got stronger and became dominant for the lowest strain energy.

In addition to the XRD analysis, the microstructures of the $\mathrm{Ti}-\mathrm{Cu}-\mathrm{N}$ films were evaluated using TEM observation. Figure 5 shows the diffractions and the cross-sectional TEM images of the films at pulse bias duty cycle of $10 \%$, $50 \%$ and $80 \%$, respectively, and a high-resolution image from the film with $50 \%$ duty cycle. Regions A, B and C showed some results of the selected area electron diffraction (SAED). From the bright field image, the microstructure shows almost equiaxed grains whose size could be estimated to be about $10-50 \mathrm{~nm}$, similar to the results of our previous work [14]. According to the morphology and diffraction pattern, the grain size increased firstly and then decreased with the pulse bias duty cycle increasing, which could be related to the next reasons. One reason is grain refining due to bias duty cycle increasing, and the other is grain refining owing to increasing the copper content $[6,31]$. Some researchers had concluded by means of theoretical analysis that the $\mathrm{Cu}$ exists as the very tiny grains dispersing around the $\mathrm{TiN}$ nanocrystallites $[6,11]$. According to some high-resolution images, we can clearly observe that the $\mathrm{Cu}$ survives as amorphous particle around the TiN crystallites, and one of them is shown in Fig. 5. Because the $\mathrm{Cu}$ cannot wet TiN, it is too difficult for $\mathrm{Cu}$ to form amorphous layer surrounding the TiN crystallites $[9,31,32]$. In this present work, we suggest that the $\mathrm{Ti}-\mathrm{Cu}-\mathrm{N}$ films are the nanocomposite films formed with $\mathrm{Cu}$ amorphous particle and TiN nanocrystallites. Anders put forward to an extended structure zone diagram used to understand the relation between energy flux and growth structure [33]. In his model, when the normalized energy flux exceeds a certain amount, the growth structure will be transformed to nanocrystalline with preferred orientation, which can be used to explain our experiment results. Due to the application of axial magnetic field, the ion quantity and energy increased compared to the conventional AIP technique. Furthermore, both the ion quantity and energy increased with duty cycle, which are favourable for the formation of nanocrystalline structure with preferred orientation.

\subsection{Morphology}

The SEM surface and cross-section images of the $\mathrm{Ti}-\mathrm{Cu}-\mathrm{N}$ films are shown in Fig. 6. Many macroparticles (MPs) were observed on the surface of the films. With the duty cycle increasing, the number and size of MPs and the sputterd craters obviously decreased. In general, the change in bias voltage amplitude will lead to variety of the sheath thickness and the quantity of particle accelerated. However, the duty cycle only affected the quantity of particle accelerated when the bias amplitude was fixed. The MPs with weak negative charges would be repeatedly charged in the pulse sheath under pulse electrical field and then were repelled by the substrate with negative bias [34]. Therefore, the higher the duty cycle, the less the MPs on the film surface. In addition, some long rod MPs were observed on the surface of the films under lower duty cycle, which were originated by mutual collision and concentration of the MPs. According to the cross-sectional images in Fig. 6, there is no obvious defect in the films and deposition rate can be calculated based on the thickness of the films.

The surface roughness $(\mathrm{Ra})$ and deposition rate of the $\mathrm{Ti}-\mathrm{Cu}-\mathrm{N}$ films as a function of duty cycle are shown in Fig. 7. It can be seen that the surface roughness decreases with the duty cycle increasing, which attributes to the less 


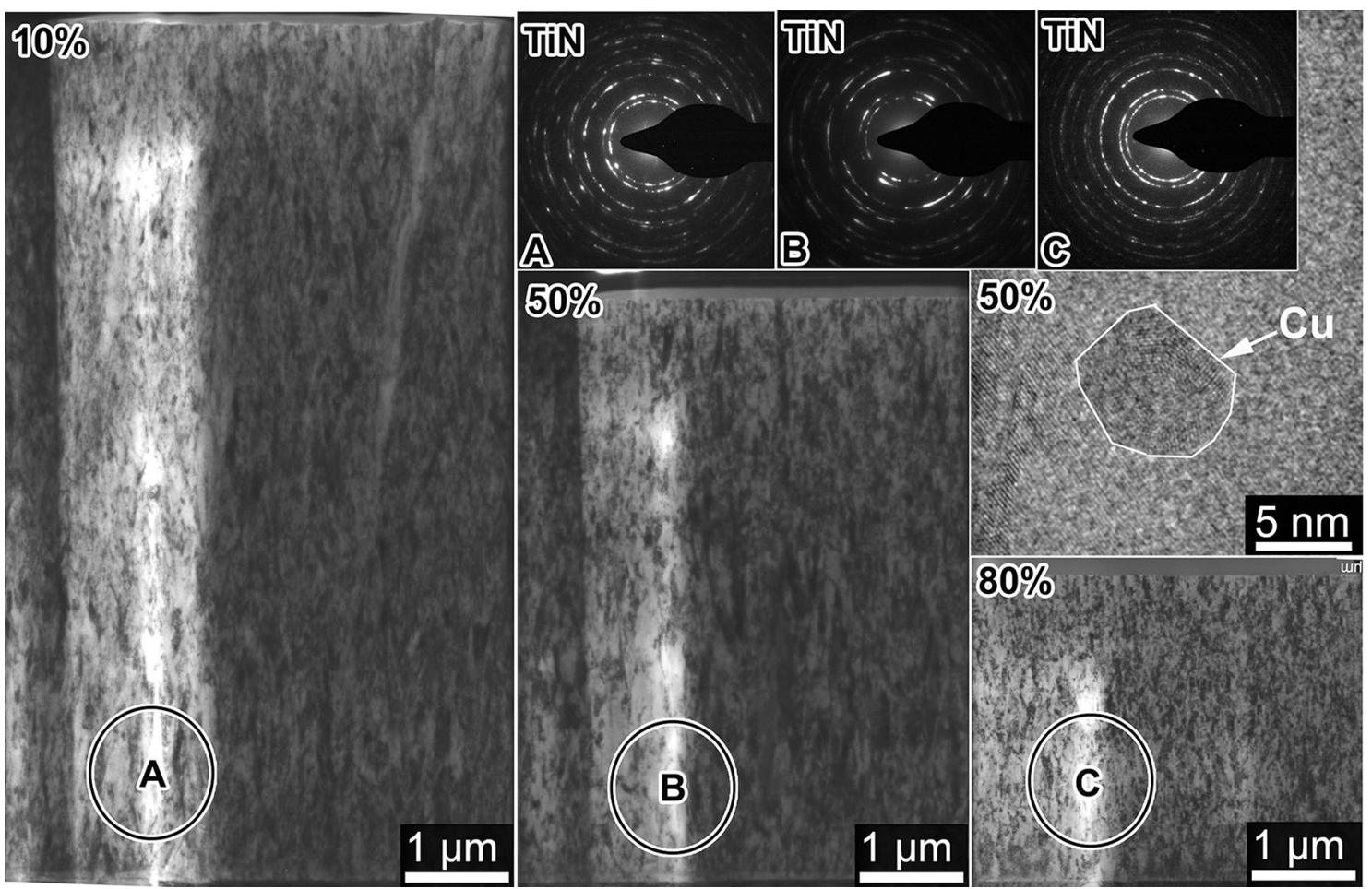

Fig. 5 A cross-sectional TEM micrographs and electron diffraction patterns of the Ti-Cu-N films with duty cycle of $10 \%$, $50 \%$ and $80 \%$, and a high-resolution photograph of the $\mathrm{Ti}-\mathrm{Cu}-\mathrm{N}$ film with duty cycle of $50 \%$

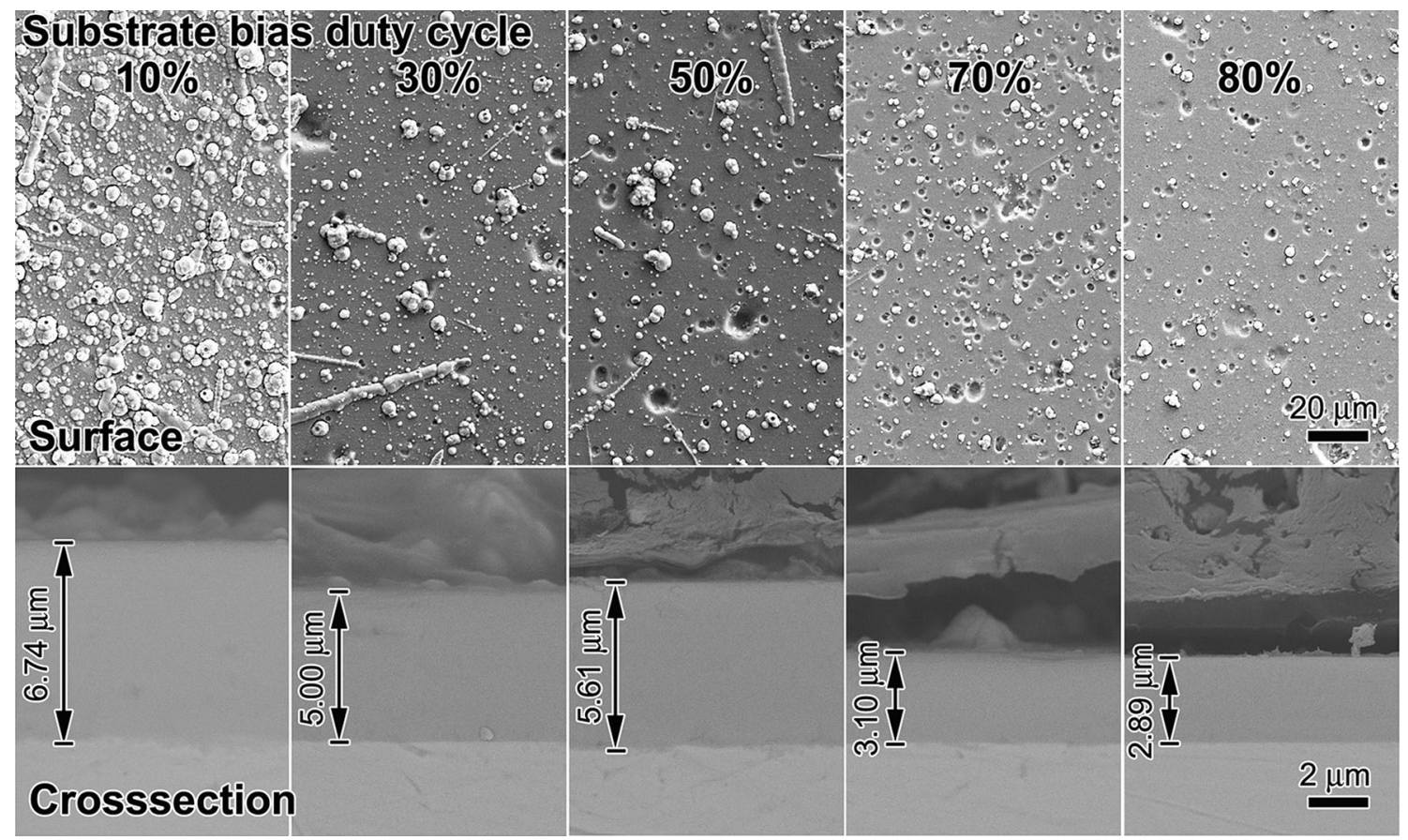

Fig. 6 SEM images of Ti-Cu-N films deposition with different duty cycles

MPs and sputtered craters on the film surface (see Fig. 6), similar to the results of Wei and Gong [17]. The deposition rate also decreases with the duty cycle increasing, probably because the increase in duty cycle could enhance ion bombardment [35], which causes more intensive resputtering during film deposition. The variation trend of deposition rate is consistent with the results from XRD 


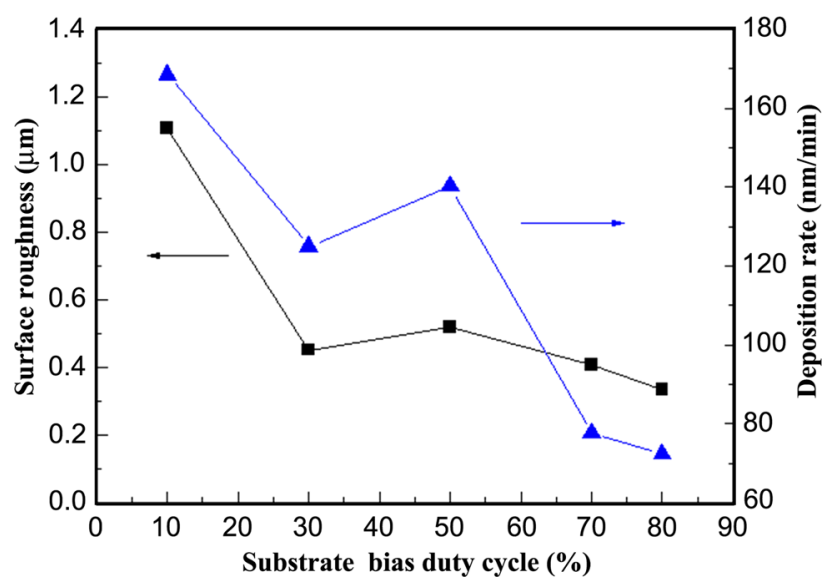

Fig. 7 Surface roughness and deposition rate of $\mathrm{Ti}-\mathrm{Cu}-\mathrm{N}$ films as a function of bias duty cycle

with the fact that the diffraction peaks of substrate increases with the duty cycle.

\subsection{Mechanical Properties}

Figure 8 shows the variations of the residual stress and the critical load of the films as a function of duty cycle. The residual stress firstly increased and then decreased with duty cycle increasing, while the critical load showed almost opposite trend. It was mentioned that the ion energy would be enhanced with duty cycle in the previous paragraph. The compressive stress increased when the film was bombarded by ions with energies of tens or hundreds of $\mathrm{eV}$ through a process of "atomic peening" [36, 37]. However, further increasing the energies of bombarding ion could cause lattice relaxation and recrystallization. The residual stresses can be relaxed by the thermal spikes, which results in the release of strain caused by the atomic peening effect [38]. Therefore, in this present work, the residual stress increases initially and decreases afterwards with duty cycle

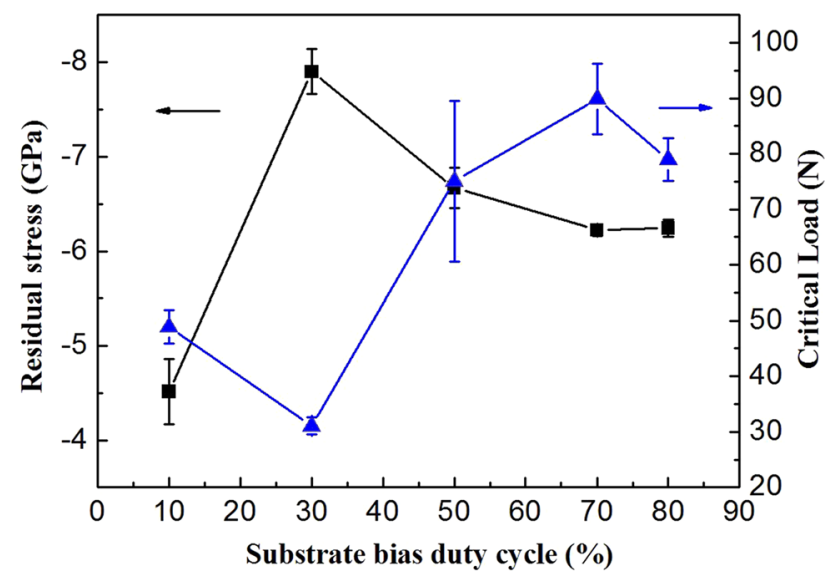

Fig. 8 Residual stress and critical load of $\mathrm{Ti}-\mathrm{Cu}-\mathrm{N}$ films as a function of bias duty cycle increasing. It is easy to find the correlation between the critical load and residual stress. The critical load rises when the residual stress declines, and vice versa.

The values of hardness $H$ and elastic modulus $E$ of the films measured by nanoindentation are presented in Fig. 9a as a function of duty cycle. They were obtained by using Oliver and Pharr's method [39]. It seemed that both the $H$ and $E$ showed almost relevant tendency as the residual stress. With the increase in duty cycle, the density of plasma and the ion bombardment were improved. The "atomic peening" effect probably dominates variation tendency of the hardness and elastic modulus. Toth's study pointed out that the texture can play a role for the film hardness when the same compositions are applied [40]. In this present work, the maximum hardness was achieved at duty cycle of $50 \%$ owing to higher stress and stronger preferred orientation. Veprek et al. [3] reviewed the origin of hardness enhancement in the nanocomposite films. It has been reported that the strengthening mechanism of the hardness of the nanocomposite film is a combination of many factors, such as chemical bonding, solution hardening, Hall-Petch strengthening and formation of a stable nanostructure. As is well known, the hardness of the common ternary nitrides (e.g. TiAlN, CrAlN, TiCN) is originated from solution hardening, but the hardness of the transition metal nitride based on nanocomposite films depends on grain boundary hardness [41]. In general, HallPetch effect is used to explain the grain boundary hardness of nanocomposite films. However, in this case, our results might be not entirely consistent with the effect. Argon and Yip provided an analytical model that explains in detail the physics of the competition between decreasing dislocation activity and increasing grain boundary shear, which results in the so-called strongest size [42, 43]. For smaller grain size, the hardness will decrease due to grain boundary shear. In this present work, the grain size of the film with

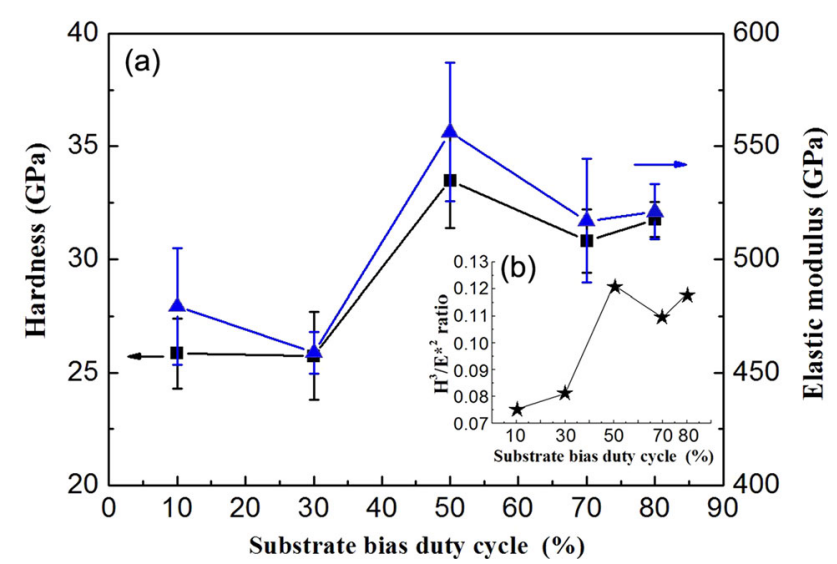

Fig. 9 Hardness, elastic modulus and $H^{3} / E^{*^{2}}$ value of Ti-Cu-N films as a function of bias duty cycle 
$50 \%$ duty cycle may be more close to the "strongest size" of the $\mathrm{Ti}-\mathrm{Cu}-\mathrm{N}$ films, and then it has the highest hardness. In addition, Myung et al. [6] reported that the $\mathrm{Ti}-\mathrm{Cu}-\mathrm{N}$ film containing approximately 1.5 at. $\% \mathrm{Cu}$ achieved maximum hardness of $45 \mathrm{GPa}$, and the hardness value will reduce no matter copper content increase or decrease. The research of Zhang et al. [44] showed that the $\mathrm{Ti}-\mathrm{Cu}-\mathrm{N}$ films reached a maximum hardness of $37 \mathrm{GPa}$ with the $\mathrm{Cu}$ content of about 0.6 at. $\%$. Their works indicated that the hardness of the $\mathrm{Ti}-\mathrm{Cu}-\mathrm{N}$ film was strongly correlated with $\mathrm{Cu}$ content. In our experiments, from $30 \%$ to $70 \%$ duty cycle, the $\mathrm{Cu}$ content of the $\mathrm{Ti}-\mathrm{Cu}-\mathrm{N}$ film was closed to 1.5 at.\% (see Fig. 2). Meanwhile, Li et al. [45] pointed out that the Ti-Cu-N film with strong TiN(111) texture will exhibit higher hardness. The interaction of $\mathrm{Cu}$ content, the grain size and the growth texture in the films determines the variation tendency of the hardness of the films with duty cycle.

The ratio $H^{3} / E^{* 2}$ is the parameter that can represent the plastic deformation resistance of materials [46]. The higher the ratio $H^{3} / E^{* 2}$, the better the wear resistance is. It can be seen that the ratio $H^{3} / E^{* 2}$ increases with duty cycle and the ratio remained higher value when the duty cycle is higher than $50 \%$ (see Fig. 9b). This means that the $\mathrm{Ti}-\mathrm{Cu}-\mathrm{N}$ film with higher duty cycle might be better wear resistance.

\subsection{Tribological Properties}

Figure 10 reveals the wear rate and friction coefficient as a function of duty cycle. The wear resistance is related to the hardness of composite films. According to Archard's law, the wear resistance of a material is proportional to its hardness [47]. The wear rate of the film was extremely high at duty cycle of $10 \%$, because its hardness was obviously lower and its number of MPs was remarkably more. It seemed that, with the increase in the duty cycle from $30 \%$

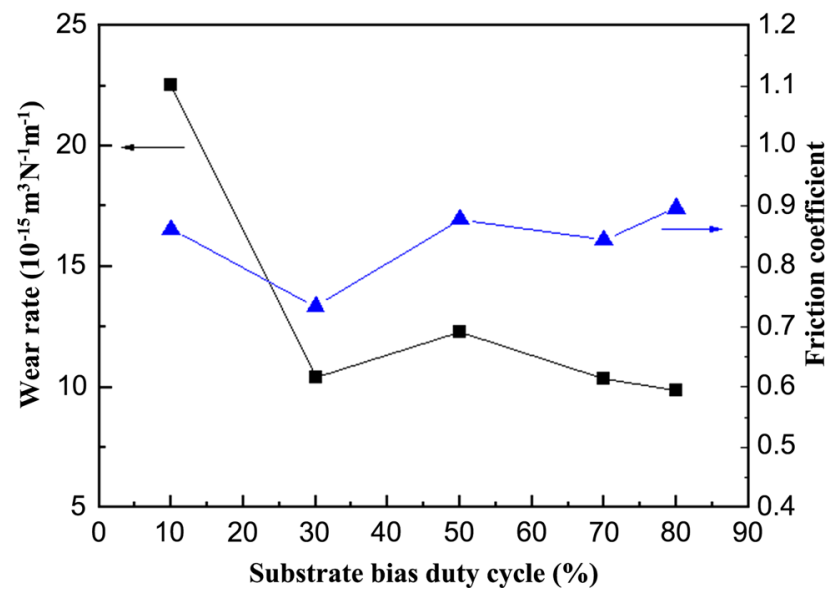

Fig. 10 Wear rate and Friction coefficient of $\mathrm{Ti}-\mathrm{Cu}-\mathrm{N}$ films as a function of bias duty cycle to $80 \%$, the wear rate of the films did not depend on the hardness and they had little change, which is roughly corresponding to the variation of the ratio $H^{3} / E^{* 2}$. In our previous work [15], the wear rate of the TiN films is $10^{-13} \mathrm{~m}^{3} \mathrm{~N}^{-1} \mathrm{~m}^{-1}$, which is higher two orders of magnitude than the Ti-Cu-N films in the present work. That indicates that the abrasive resistance of the films got significant improvement due to the addition of $\mathrm{Cu}$ in TiN films. As can be seen, the average friction coefficient of the films shows little difference with the different duty cycles. In some results, the friction coefficient of the $\mathrm{Ti}-\mathrm{Cu}-\mathrm{N}$ films is less than $0.5[6,26,48]$. However, in our tests, the friction coefficients of the films are almost close to 1.0 and even higher than of most TiN films, which is similar to the results from Ozturk et al. [49]. We considered that the "crystal chemical" approach put forward by Erdemir [50] can be used to explain the tribological behaviour in this case. According to this approach, those oxides or oxide mixtures with higher difference of ionic potentials are more likely to present low friction. Conversely, the presence of those oxides with lower difference of ionic potentials will cause high friction. In these experiments, the surface of the $\mathrm{Ti}-\mathrm{Cu}-\mathrm{N}$ films during friction will form titanium oxides and copper oxide and their ionic potentials difference is rather small, which caused high friction coefficients of the films. Guo et al. [51] reported that the friction coefficients of the $\mathrm{AlCuN}$ nanocomposite films are also close to 1.0 and the wear rate gets $1.3 \times 10^{-16} \mathrm{~m}^{3} \mathrm{~N}^{-1} \mathrm{~m}^{-1}$ due to the dense microstructure in the films. Our results are higher two orders than the results of Guo et al., which may be related to higher residual stresses in the films.

Figure 11 shows the wear scars morphologies of the Ti$\mathrm{Cu}-\mathrm{N}$ films. It was easy to find that there is no crack and abscission in all the wear scars. For most of the tribological applications, the most commonly encountered wear types are: adhesive, abrasive, fatigue and chemical (or corrosive). Now that the micro-plough does not exist on the wear scars; the wear mechanisms of the $\mathrm{Ti}-\mathrm{Cu}-\mathrm{N}$ films should be belonging to abrasive wear. The review summarized by Homlberg et al. [52] pointed out that the hard films on softer substrate can make friction and wear decrease by preventing ploughing both on a macroscale and a microscale. By EDS measurement, the wear debris mainly originate from $\mathrm{Al}_{2} \mathrm{O}_{3}$ wear ball. In particular, for the film under the duty cycle of $10 \%$, some debris adhered to the surface of the film, which led to larger wear scar and wear rate.

\section{Conclusion}

Ti-Cu-N films have been deposited on SS substrates by magnetic field-enhanced arc ion plating system. The pulse bias duty cycle had obviously influence on the 


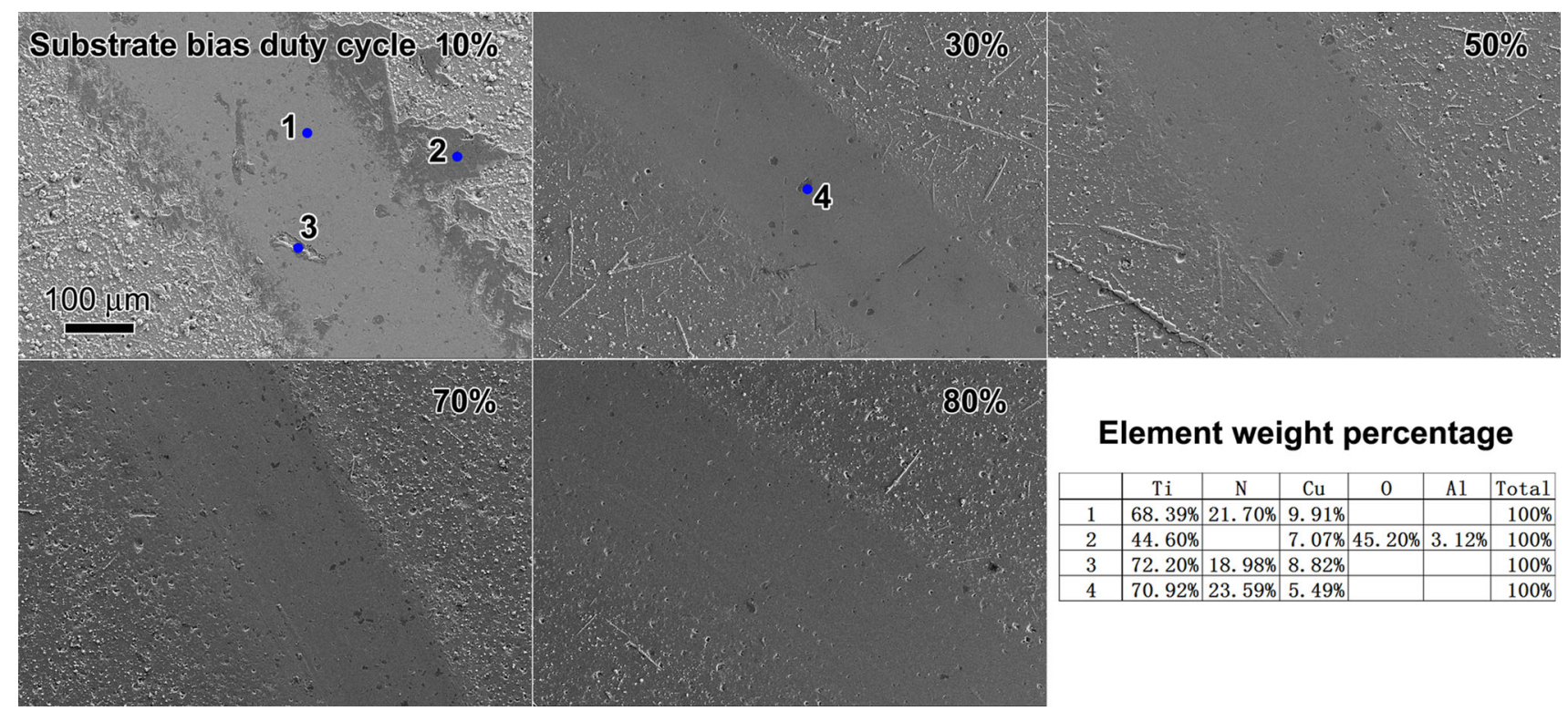

Fig. 11 Wear scar morphologies of $\mathrm{Ti}-\mathrm{Cu}-\mathrm{N}$ film at different duty cycles

composition, structure and properties of $\mathrm{Ti}-\mathrm{Cu}-\mathrm{N}$ films. With the increase in substrate pulse bias duty cycle, the texture transformed from $\operatorname{TiN}(200)$ to $\mathrm{TiN}(111)$, and the grain size firstly increased and then decreased. Due to gradually enhanced ion bombardment, resputtering effect is more enhanced, and then surface roughness and deposition rate decrease. The residual stress and hardness increase initially and decrease afterwards with the increase in duty cycle, while the variation of critical load is reverse. Except for the film under duty cycle of $10 \%$, the films show better wear resistance. The film with duty cycle of $50 \%$ showed the better comprehensive mechanical properties, including higher hardness, proper stress, better adhesion and lower wear rate. Such optimization process of duty cycle would be quite favourable for industrial application in the future.

Acknowledgements This work was supported by the National Natural Science Foundation of China (Grant No. 51401128) and Shenzhen Science and Technology Project (No. JCYJ20140508155916426).

\section{References}

[1] E. Bergmann, J. Vogel, L. Simmen, Thin Solid Films 153, 219 (1987)

[2] I. Goldfarb, J. Pelleg, Z. Zevin, N. Croitoru, Thin Solid Films 200, 117 (1991)

[3] S. Veprek, M.G.J. Veprek-Heijman, P. Karvankova, J. Prochazka, Thin Solid Films 476, 1 (2005)

[4] A.A. Voevodin, J.S. Zabinski, Compos. Sci. Technol. 65, 741 (2005)

[5] J. Musil, Surf. Coat. Technol. 125, 322 (2000)

[6] H.S. Myung, H.M. Lee, L.R. Shaginyan, J.G. Han, Surf. Coat. Technol. 163-164, 591 (2003)
[7] H.B. Wu, X.Y. Zhang, X.J. He, M. Li, X.B. Huang, R.Q. Hang, B. Tang, Appl. Surf. Sci. 317, 614 (2014)

[8] F. Pinakidou, M. Katsikini, P. Patsalas, G. Abadias, E.C. Paloura, J. Nano Res. 6, 43 (2009)

[9] Z.G. Li, S. Miyake, M. Kumagai, H. Saito, Y. Muramatsu, Surf. Coat. Technol. 183, 62 (2004)

[10] H.S. Myung, J.G. Han, J.H. Boo, Surf. Coat. Technol. 177-178, 404 (2004)

[11] L. Zhang, G.J. Ma, G.Q. Lin, K.C. Han, H. Ma, Nucl. Instr. Methods Phys. Res. B 320, 17 (2014)

[12] W. Olbrich, J. Fessmann, G. Kampschulte, J. Ebberink, Surf. Coat. Technol. 49, 258 (1991)

[13] G.Q. Lin, Y.H. Zhao, H.M. Guo, D.Z. Wang, C. Dong, R.F. Huang, L.S. Wen, J. Vac. Sci. Technol. A 22, 1218 (2004)

[14] Y.H. Zhao, X.Q. Wang, J.Q. Xiao, B.H. Yu, F.Q. Li, Appl. Surf. Sci. 258, 370 (2011)

[15] Y.H. Zhao, W.J. Yang, C.Q. Guo, Y.Q. Chen, B.H. Yu, J.Q. Xiao, Acta Metall. Sin. (Engl. Lett.) 28, 984 (2015)

[16] Y.H. Zhao, L. Xu, C.Q. Guo, W.J. Yang, G.Q. Lin, B.H. Yu, Acta Metall. Sin. (Engl. Lett.) 29, 546 (2016)

[17] Y.Q. Wei, C.Z. Gong, Appl. Surf. Sci. 257, 7881 (2011)

[18] H. Nakazawa, R. Kamata, S. Miura, S. Okuno, Thin Solid Films 539, 134 (2013)

[19] Y. Wang, C.H. Zhao, Z.X. Song, F. Cao, D.W. Yang, Appl. Surf. Sci. 253, 8858 (2007)

[20] L. Wang, S.H. Zhang, Z. Chen, J.L. Li, M.X. Li, Appl. Surf. Sci. 258, 3629 (2012)

[21] S.S. Zhao, H. Du, W.G. Hua, J. Gong, J.B. Li, C. Sun, J. Mater. Res. 22, 2659 (2007)

[22] T.G. Wang, D. Jeong, Y.M. Liu, Q.M. Wang, S. Iyengar, S. Melin, K.H. Kim, Surf. Coat. Technol. 206, 2638 (2012)

[23] J.E. Sundgren, B.O. Johansson, S.E. Karlsson, Thin Solid Films 105, 383 (1983)

[24] V.S. Smentkowski, Prog. Surf. Sci. 64, 1 (2000)

[25] L. Tian, Y. Zhang, Y. Ma, X. Zhu, B. Tang, Surf. Coat. Technol. 228, S495 (2013)

[26] H.F. Wang, X.F. Shu, M.Q. Guo, D. Huang, Z.G. Li, X.Y. Li, B. Tang, Surf. Coat. Technol. 235, 235 (2013)

[27] P. Martin, A. Bendavid, T. Kinder, I.E.E.E. Trans, Plasma Sci. 25, 675 (1997) 
[28] G.Q. Yu, B.K. Tay, S.P. Lau, K. Prasad, L.K. Pan, J.W. Chai, D. Lai, Chem. Phys. Lett. 374, 264 (2003)

[29] H. Jiménez, E. Restrepo, A. Devia, Surf. Coat. Technol. 201, 1594 (2006)

[30] J. Pelleg, L.Z. Zevin, S. Lungo, N. Croitoru, Thin Solid Films 197, 117 (1991)

[31] J.L. He, Y. Setsuhara, I. Shimizu, S. Miyake, Surf. Coat. Technol. 137, 38 (2001)

[32] P. Xiao, B. Derby, Acta Mater. 44, 307 (1996)

[33] A. Anders, Thin Solid Films 518, 4087 (2010)

[34] M.D. Huang, G.Q. Lin, Y.H. Zhao, C. Sun, L.S. Wen, C. Dong, Surf. Coat. Technol. 176, 109 (2003)

[35] D.M. Mattox, J. Vac. Sci. Technol. A 7, 1105 (1989)

[36] G. Carter, J. Phys. D Appl. Phys. 27, 1046 (1994)

[37] G.C.A.M. Janssen, Thin Solid Films 515, 6654 (2007)

[38] C.A. Davis, Thin Solid Films 226, 30 (1993)

[39] W.C. Oliver, G.M. Pharr, J. Mater. Res. 7, 1564 (1992)

[40] L.E. Toth, Transition Metal Carbides and Nitrides (Academic, New York, 1971)
[41] S. Zhang, Nanostructured Thin Films and Coatings: Mechanical Properties (CRC, Boca Raton, 2010)

[42] S. Yip, Nature 391, 532 (1998)

[43] A.S. Argon, S. Yip, Philos. Mag. Lett. 86, 713 (2006)

[44] L. Zhang, G.J. Ma, G.Q. Lin, K.C. Han, H. Ma, Nucl. Instrum. Phys. Res. B 320, 17 (2014)

[45] Z.G. Li, J.L. He, T. Matsumoto, T. Mori, S. Miyake, Y. Muramatsu, Surf. Coat. Technol. 174-175, 1140 (2003)

[46] J. Musil, R. Daniel, Surf. Coat. Technol. 166, 243 (2003)

[47] J. Archard, Wear 113, 3 (1986)

[48] J.X. Li, H.Q. Zhang, A. Fan, B. Tang, Surf. Coat. Technol. 294, 30 (2016)

[49] A. Ozturk, K.V. Ezirmik, K. Kazmanl1, M. Urgen, O.L. Eryılmaz, A. Erdemir, Tribol. Int. 41, 49 (2008)

[50] A. Erdemir, Surf. Coat. Technol. 200, 1792 (2005)

[51] J. Guo, H.Y. Wang, F.P. Meng, X. Liu, F. Huang, Surf. Coat. Technol. 228, 68 (2013)

[52] K. Homlberg, H. Ronkainen, A. Matthews, Ceram. Int. 26, 787 (2000) 